\title{
Proteomics for Toxicological Pathways Screening: A Case Comparison of Low-concentration Ionic and Nanoparticulate Silver
}

\author{
Pawitrabhorn Samutrtai, ${ }^{* \dagger}$ Sucheewin Krobthong, ${ }^{* *}$ and Sittiruk RoyTraKuL ${ }^{* *}$ \\ *National Nanotechnology Center (NANOTEC), National Science and Technology Development Agency \\ (NSTDA), Pathum Thani 12120, Thailand \\ **Proteomics Research Laboratory, Genome Technology Research Unit, BIOTEC, National Science and \\ Technology Development Agency, Pathum Thani 12120, Thailand
}

\begin{abstract}
LC-MS/MS-based proteomics coupled with an online bioinformatics platform was under evaluation for applicability to toxicological pathways evaluation at low cytotoxic concentration $\left(\mathrm{LC}_{10}\right)$ of silver nanoparticles $(\mathrm{AgNP})$ and ionic silver in human carcinoma cells after $48 \mathrm{~h}$ of exposure. Significantly, differentially-expressed proteins (One-way ANOVA, $p<0.05)$ with more than 4-fold compared to the control were subjected to functional pathway analysis by STITCH. SOTA clustering indicated a similarity of the protein expression between AgNP and the control group. We established a resemblance of proteins in the cell cycle pathway affected by both Ag substances. The differences in the toxicological pathways from $\mathrm{AgNO}_{3}$ were involved in the cellular organization and metabolic process of macromolecules, while the nucleic acid metabolic process was altered by AgNP. The present study supported the practicability of LC-MS/MS-based proteomics coupled with STITCH for the identification of toxicological pathways in both silvers. We appraised this platform technology to be promising and powerful for a toxicological screening of other new substances.
\end{abstract}

Keywords Bioinformatics, LC-MS/MS, silver, proteomics, toxicological pathways analysis

(Received January 20, 2020; Accepted February 18, 2020; Advance Publication Released Online by J-STAGE February 28, 2020)

\section{Introduction}

Nanotechnology has brought an expansion in engineered nanoparticles production, in which their specific properties have been exploited to various fields of utilization. ${ }^{1}$ Silver nanoparticles (AgNPs) are among the highest manufactured substances with progressive applications in industry, medicine, and household products ${ }^{2,3}$ due to their novel characteristics in antimicrobial activity. ${ }^{4}$ Given an increase in the number of nanosilver-enabled products, the complete understanding of toxicological pathways from these particles is still insufficient. Therefore, research to provide a comprehensive impact from these materials on biological systems is extremely essential. ${ }^{5}$ Although it has been reported that the predominant adverse effects, such as oxidative stress, DNA damage, inflammation, genotoxicity, and cell death were involved in AgNPs exposure in various cell lines. ${ }^{3,6,7}$ These observations were based on highconcentration exposure, generally in parts per million (ppm), which might not correctly indicate the exposure in real life. ${ }^{8}$ Moreover, the functionalization of engineered AgNPs has burdened the toxicological studies as the different characteristics resulting in alternated potential toxicities. In addition, due to their high surface area and low redox potential, AgNPs are prone to release ionic silver $\left(\mathrm{Ag}^{+}\right) .{ }^{9}$ It is controversial whether the toxic effects from AgNP could derive from either released $\mathrm{Ag}^{+}$, the nanoparticulate form, or both. ${ }^{1}$ Therefore, the platform

† To whom correspondence should be addressed.

E-mail: pawitrabhorn.sam@nanotec.or.th of toxicological study, especially for the fast-paced development of AgNPs, requires a powerful technique that enables quick analysis and is capable of elucidating the toxicological pathways from different types of silver.

Quantitative liquid chromatography coupled to tandem mass spectrometry (LC-MS/MS) based proteomics is an alternative approach to assess a large number of proteins under a short period of time. ${ }^{10}$ Coupled with bioinformatics, proteins are identified and their relative abundance can be compared between samples; thus, the changes in protein expression are established among samples. ${ }^{11,12}$ Protein-chemical interaction network, e.g. STITCH, is a powerful tool to establish the associated pathways of chemicals and proteins from various resources, e.g. KEGG, Metacyc, and Reactome. ${ }^{13}$ The combination of proteomics and STITCH has reportedly been used for the identification of specific biomarkers of various diseases, e.g. tuberculosis, ${ }^{14}$ malaria, ${ }^{15}$ and cholangiocarcinoma, ${ }^{18}$ as well as for the determination of homologous proteins between human and canine saliva. ${ }^{16}$ However, this was limitedly adopted for the identification of comprehensive pathways, which is important for toxicological research. This approach would allow for the prediction of toxicological pathways from AgNP under a lowdose condition, in which the initial cellular responses (protein alterations, metabolic reactions and regulatory cascades in cells) are adjusted. This coupled approach offers a high-speed screening, which is extremely required to pursue advances in nanotechnology. In this study, we investigated the applicability of LC-MS/MS-based proteomics coupled with STITCH interaction mapping for the identification of toxicological pathways. We also established a comparison between the 
(A) (B)

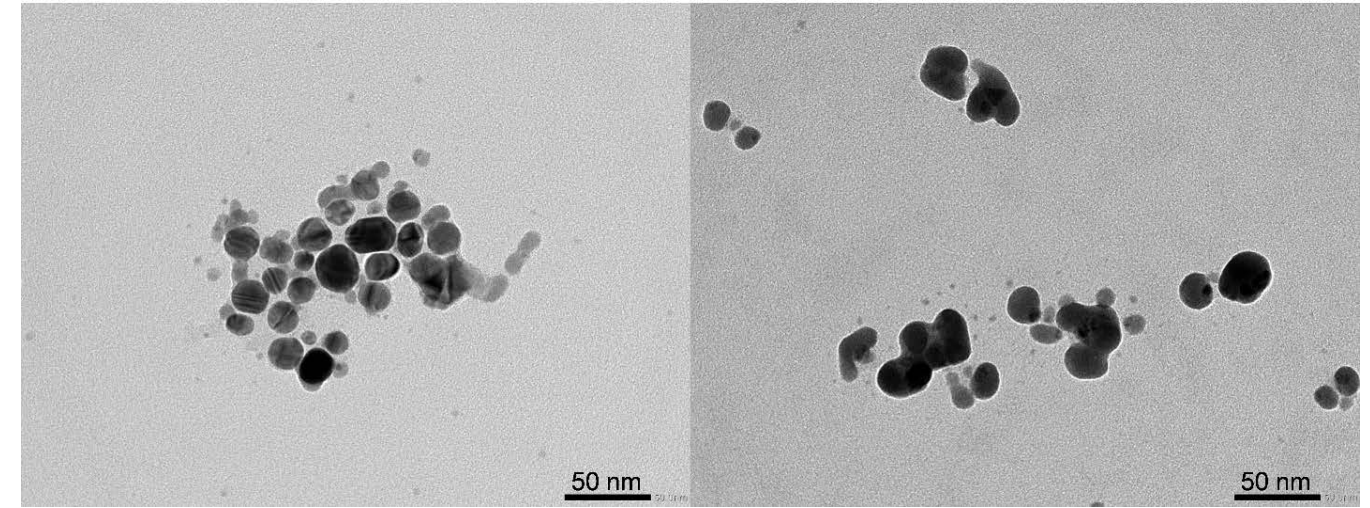

Fig. 1 TEM images of AgNP in (A) DI water, and (B) in DMEM. The primary shape of AgNP was spherical with a primary size of $16.88 \pm 4.54 \mathrm{~nm}$ in DI water and was aggregated in DMEM with increasing size to $137.67 \pm 37.69 \mathrm{~nm}$.

toxicological pathways from AgNP and ionic silver in a screening model, human skin carcinoma cell line (A431), at the concentration of $\mathrm{LC}_{10}$ after $48 \mathrm{~h}$ of exposure to exhibit the low concentration and chronic response in a realistic exposure scenario, in which most proteins are active.

\section{Experimental}

\section{Cell culture and AgNP exposure}

A human skin carcinoma cell line (A431) was obtained from American Type Culture Collection (ATCC; Manassas, VA, USA) and was cultured in an exposure medium, Dulbecco's modified Eagle medium (DMEM) containing 10\% fetal bovine serum (FBS) and $1 \%$ GlutaMax $^{\mathrm{TM}}$ (Gibco $^{\mathrm{TM}}$; Thermofisher Scientific, Waltham, MA, USA) at $37^{\circ} \mathrm{C}$ in a $5 \% \mathrm{CO}_{2}$ atmosphere. $\mathrm{AgNP}\left(20 \mathrm{~nm}\right.$, stabilized by citrate) and $\mathrm{AgNO}_{3}$ were purchased from Sigma-Aldrich (Munich, Germany). AgNP stock solution was prepared by sonication at $37 \mathrm{kHz}$ for 15 min before spiking into the exposure medium. Cells with less than 25 passages, $70-80 \%$ confluency, were used for the tests. Cells were exposed to silver substances at the concentration of $\mathrm{LC}_{10}$ (calculated by the logistic regression of viability data) for $48 \mathrm{~h}$ prior to preparation for a proteomics study. The nontreated cells, classified as the control group, were maintained for $48 \mathrm{~h}$ before collection for proteomics. The exposure condition was chosen to collect protein expression data in a chronic exposure scenario, in which proteins are still functioning for cellular homeostasis regulation.

\section{Physicochemical characterization of AgNP}

The primary size and morphology of AgNP were identified using a transmission electron microscope (TEM; JEM-2100 plus; JEOL Ltd., Tokyo, Japan). The hydrodynamic diameter of AgNP in deionized water and the exposure medium was measured by dynamic light scattering (DLS) using ZetaSizer Nano-ZS (Malvern Instruments, Worcestershire WR, UK), in which the zeta-potential was also examined. The dissolved ionic silver after 48-h incubation in the medium was analyzed in the supernatant fraction after $20000 \times g, 1 \mathrm{~h}$ centrifugation using inductively coupled plasma mass spectrometry (ICP-MS) (Agilent 7900 ICP-MS; Agilent, Santa Clara, CA, USA).

\section{Protein extraction and digestion}

Cell lysate was prepared by sonication at $20 \mathrm{~Hz}$ for $5 \mathrm{~s}$. Protein was purified by cold-acetone precipitation (1:5 (v/v)) and solubilized by $0.1 \%$ RapidGest SF (Waters, UK) in $20 \mathrm{mM}$ ammonium bicarbonate. The concentration of protein was determined using Lowry's method. The amount of $3 \mu \mathrm{g}$ protein was reduced $\left(5 \mathrm{mM}\right.$ dithiothreitol; DTT, $\left.72^{\circ} \mathrm{C}, 30 \mathrm{~min}\right)$ and alkylated (15 mM Iodoacetamide; IAA, RT in the dark, $1 \mathrm{~h}$ ) prior to digestion using trypsin (Sequencing grade modified trypsin; Promega, Madison, WI Promega, Madison, WI, USA) at a 1:20 trypsin/protein concentration ratio $\left(37^{\circ} \mathrm{C}, 4 \mathrm{~h}\right)$. The mixture was evaporated and re-suspended with $0.1 \%$ formic acid (FA) (LC-MS grade FA; Sigma-Aldrich, Munich, Germany) in LC-MS grade water (J. T. Baker, USA).

\section{LC-MS/MS analysis}

An LC-MS/MS quantitative proteomics study was performed by Synapt HDMS ${ }^{\mathrm{TM}}$ (Waters Corp.; Milford, MA). The amount of $150 \mathrm{ng}$ of each sample was injected onto a NanoAcquity system (Waters Corp., Milford, MA, USA), consisting of a trapping column $(\mathrm{C} 18,5 \mu \mathrm{m}, 180 \mu \mathrm{m} \times 20 \mathrm{~mm})$ and a BEH130 analytical reversed-phase column $(\mathrm{C} 18,1.7 \mu \mathrm{m}, 100-\mu \mathrm{m} \times 100$ $\mathrm{mm})$. Chromatographic separation was achieved using a linear gradient of $0.1 \% \mathrm{FA}$ in water and in acetonitrile $(\mathrm{ACN})$ for 50 min. Mass spectra were acquired at $+2,+3$, and +4 charge state and $\mathrm{m} / \mathrm{z}$ range of $300-1800$ from data-independent acquisition (DIA) using MSE-mode.

\section{Protein quantification and identification}

Protein was quantified by Progenesis ${ }^{\circledR}$ QI for proteomics (Nonlinear Dynamics, Newcastle upon Tyne, UK). Raw MS spectra were imported into the software using lock mass calibration $(\mathrm{m} / \mathrm{z}=784.8625 ;$ [Glu1]-Fibrinopeptide $)$ and identified against UniProt/Swiss-Prot human databases (UniProtKB released in August 2018) with the following parameters: peptide tolerance, $50 \mathrm{ppm}$; fragment tolerance, $20 \mathrm{ppm}$; minimum fragment ion matches per peptide, 2; minimum fragment ion matches per protein, 3 ; minimum peptide ion matches per protein, 1; fixed modifications, cysteine carbamidomethylation (C); variable modifications, methionine oxidation $(\mathrm{M})$, asparagine and glutamine deamination (NQ).

\section{Experimental design and statistical rationale}

A proteomics approach was achieved using three biological 
replicates of each condition. The normalization of protein abundances was performed simultaneously in Progenesis ${ }^{\circledR}$ Q for proteomics, in which one sample was selected as a reference to calculate the global scaling factor to be applied to other samples. Differentially expressed proteins among treatment conditions were identified using one-way analysis of the variance (ANOVA) at a confidence level of $95 \%$. Differentially regulated proteins between treatment groups were clustered by Self-Organizing Tree Algorithm (SOTA) using the Euclidean distance in Multiple Experiment Viewer (MeV) Ver. 4.9.0. The pathway of proteins in each cluster was identified by the PANTHER classification system. Proteins with $\geq 4$-fold expression compared to the control were further used for protein-protein interaction mapping by STITCH Ver. 5.0 (http:// stitch.embl.de/)

\section{Results}

\section{Physicochemical characteristics of AgNP}

TEM images indicated that the primary shape of AgNP in deionized (DI) water was spherical with an average size of $16.88 \pm 4.54 \mathrm{~nm}$. In an exposure medium, the aggregation of AgNP was observed with an increase in primary size to 137.67 \pm 37.69 , as depicted in Fig. 1. Dynamic light scattering analysis showed an increase in the hydrodynamic diameter of AgNP in the exposure medium with a high polydispersity index (PdI) of $>0.5$, supporting AgNP aggregation. Zeta-potential indicated that AgNP were very stable in DI water, and moderately stable in DMEM, as reported in Table 1. The dissolution of AgNP by ICP-MS quantified that $70.57 \%$ of ionic $\mathrm{Ag}$ was released from AgNP after $48 \mathrm{~h}$ of incubation.

Table 1 Primary size, hydrodynamic size, and zeta potential of AgNP in different media

\begin{tabular}{lccc}
\hline \multicolumn{1}{c}{ Media } & $\begin{array}{c}\text { Primary } \\
\text { size/nm }\end{array}$ & $\begin{array}{c}\text { Hydrodynamic } \\
\text { size/nm }\end{array}$ & $\begin{array}{c}\text { Zeta-potential/ } \\
\mathrm{mV}\end{array}$ \\
\hline Deionized water & $16.88 \pm 4.54$ & $152.5 \pm 5.6$ & $-35.6 \pm 1.6$ \\
DMEM & $137.67 \pm 37.69$ & $1190 \pm 84$ & $-14.9 \pm 0.9$ \\
\hline
\end{tabular}

a. Transmission electron microscopy (TEM).

b. Dynamic light scattering (DLS).

\section{Proteomics analysis of different silver treatment}

According to Principal Component Analysis (PCA), there was a significant difference of the protein features in $\mathrm{AgNP}, \mathrm{AgNO}_{3}$, and control groups, while the variation within replicate of each treatment was not established, as shown in Fig. 2. The functions of all retrieved proteins across the PANTHER classification system under the Gene Ontology (GO) biological process showed that the majority of these proteins were involved in the cellular process, metabolic process, and biological regulation, as shown in Fig. 3. SOTA clustering grouped these proteins into 11 clusters based on their expression between samples, as shown in Fig. 4. The function of the proteins in each cluster was identified by the PANTHER pathway. From SOTA clustering, it was shown that the expression of proteins in AgNP and the control groups was relatively identical, while proteins in the $\mathrm{AgNO}_{3}$ group were distinctly different. The pathways of highabundant proteins in three upper clusters were Huntington diseases and integrin signaling pathway, whereas the pathway of low-abundant proteins in two lower clusters was platelet-derived growth factor (PDGF) signaling pathway. The total number of proteins with unique peptide counts was 901 and was categorically depicted by fold-change to the control, as shown in Fig. 5.

\section{Potential toxicological pathways of silver treatment}

The protein-protein interaction map, as illustrated in Fig. 6 , indicated the majority of $>4.01$-fold expressed in silver treatment compared to the control were up-regulated, with one protein down-regulated in $\mathrm{AgNO}_{3}$ exposure. The pathways of these proteins were analyzed by STITCH based on Gene Ontology (GO) biological process. The top-three potential pathways of the $\mathrm{AgNO}_{3}$ treatment were chromatin modification (GO:0016568), histone deacetylation (GO:0016575), and regulation of the mitotic metaphase/anaphase transition (GO:0030071). While mitotic chromosome condensation (GO:0007076), mitotic sister chromatid segregation (GO:0000070), and mitotic nuclear division (GO:0007067) were affected by AgNP exposure. Lists of potential pathways enriched by STITCH are given in Tables 2 and 3 for proteins identified in $\mathrm{AgNO}_{3}$ and $\mathrm{AgNP}$, respectively.

\section{Discussion}

Although it was demonstrated that AgNPs induced toxic effects in various models (AshaRani et al., 2012; Johnston et al., 2010;

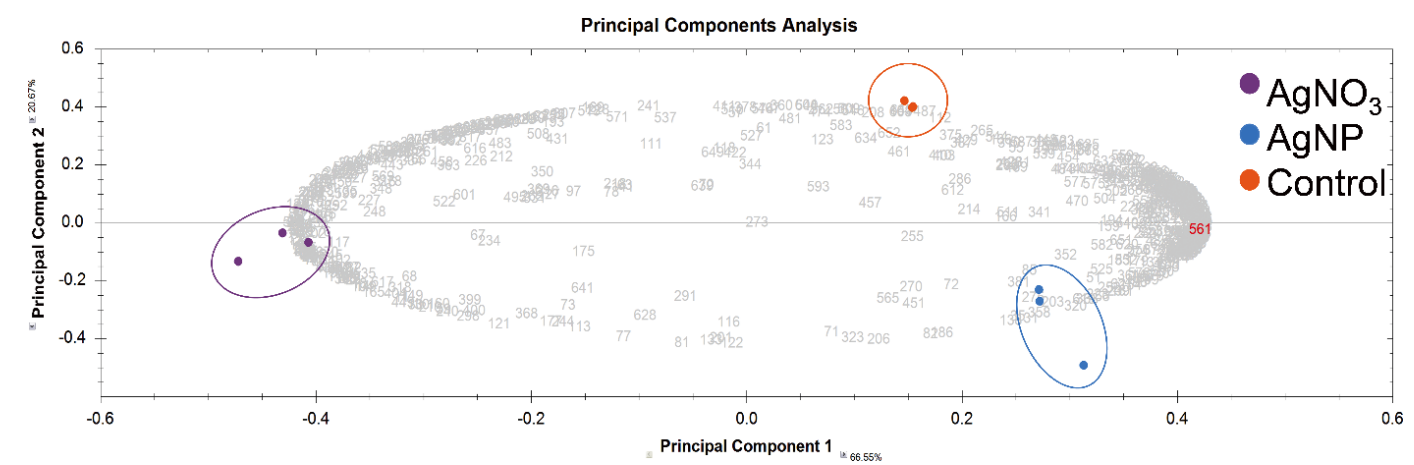

Fig. 2 PCA analysis of protein abundance in different treatment samples. The cluster of $\mathrm{AgNO}_{3}$ is shown in purple, AgNP in blue, and control in orange. The high distance of each cluster indicates the variation in protein between samples, while the replicate of protein from the same treatment forms a small cluster depicts the small variation of protein in the same treatment. 


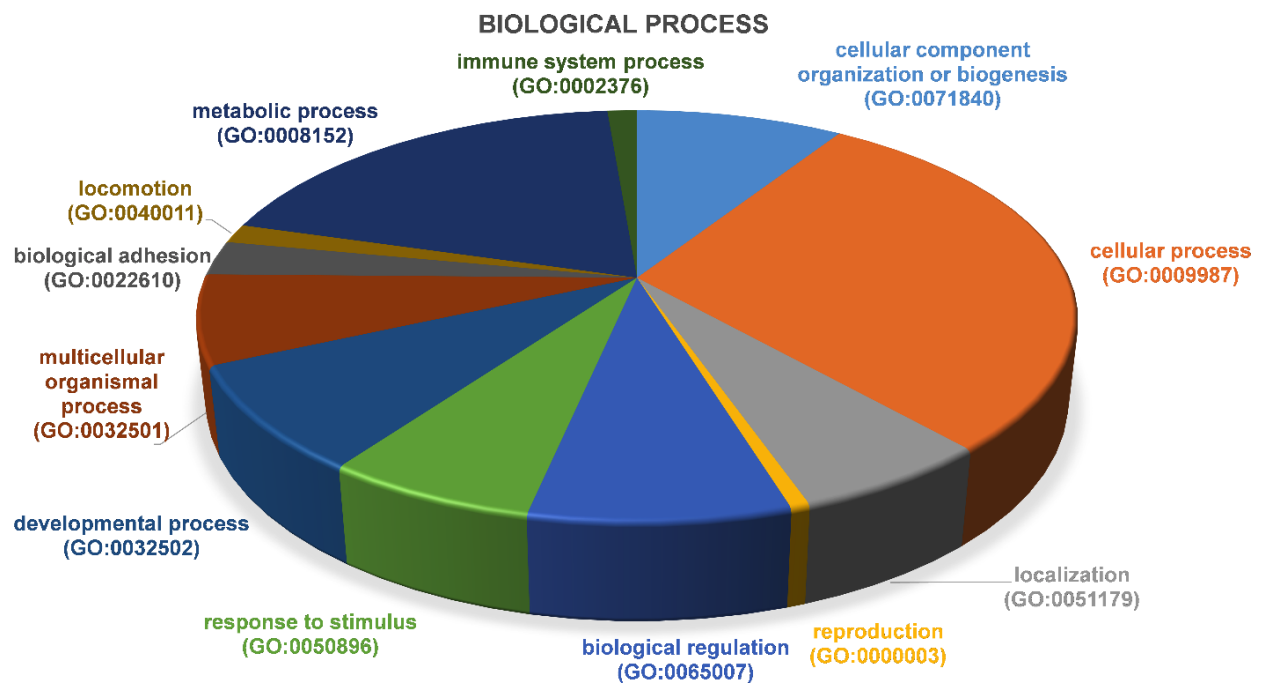

Fig. 3 PANTHER classification of the biological process of 1258 proteins identified from LC-MS/MS regardless of the sample treatment. The majority of these proteins was functioned in cellular processes.

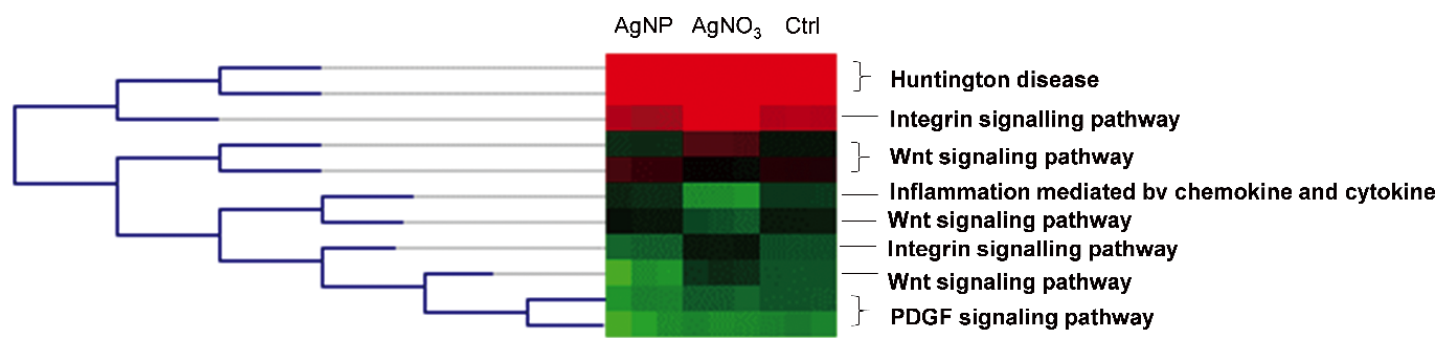

Fig. 4 SOTA dendrogram of protein abundance by samples. The heat-map shows the similarity of protein abundance in control and AgNP groups. Proteins were grouped into 11 clusters with different PANTHER pathway identification.

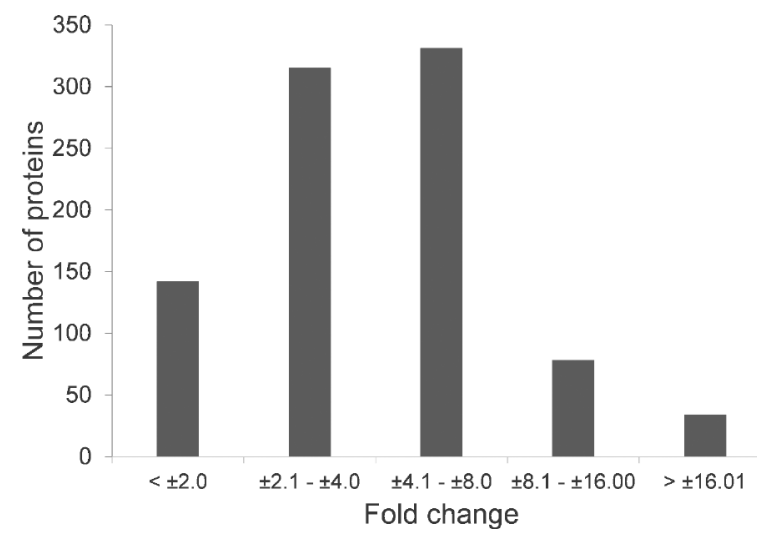

Fig. 5 Proteins with unique protein counts were categorized by foldchange compared to the control. The highest fold-change was $\pm 4.0- \pm 8.0$.

Zhang, Wang, Chen, and Chen, 2014), mostly, the concluded results were based on high concentration, which might not indicate the possible adverse effects of AgNPs $(\mathrm{Hu}, \mathrm{Li}, \mathrm{Gao}$, $\mathrm{Mu}$, and Zhou, 2016). Moreover, knowledge about the toxicological pathways of AgNPs is limited, which may hinder our understanding regarding AgNP safety. The toxicological pathways from NPs can be focused at the molecular levels, i.e. genes and proteins. Although proteins are translated from messenger RNA (mRNA), which are represented by genes, these molecular endpoints are not concomitantly expressed as protein can undergo a variety of modifications, e.g. alternative splicing, post-translational modifications (PTMs), etc., to serve the maintenance of cell function, regulation, and response to damage. Therefore, the measurement of protein abundance can relatively indicate the cellular condition. A quantitative proteomics approach provides information concerning the alteration of protein expression between groups of samples. ${ }^{17}$ Therefore, proteomics study is useful to investigate the disturbance in cell function at the protein level, which consequently reveals the toxicological pathways induced by NPs exposure.

There are several methods to analyze the differentially expressed proteins. However, some conventional methods, for example, two-dimensional gel electrophoresis (2-DE), may have drawbacks for nanotoxicological applications. Given the advance in nanotechnology, and a large variety of NPs are currently introduced into the consumer market, this approach may not be suitable for the screening of NPs toxicity as it is time-consuming and challenging for automation. ${ }^{19}$ Due to the requirement of a high-throughput workflow in nanotoxicological field, LC-MS/MS-based proteomics might be a better option to study the differential protein expression induced by NPs, since it allows for the complete analysis of proteins using 


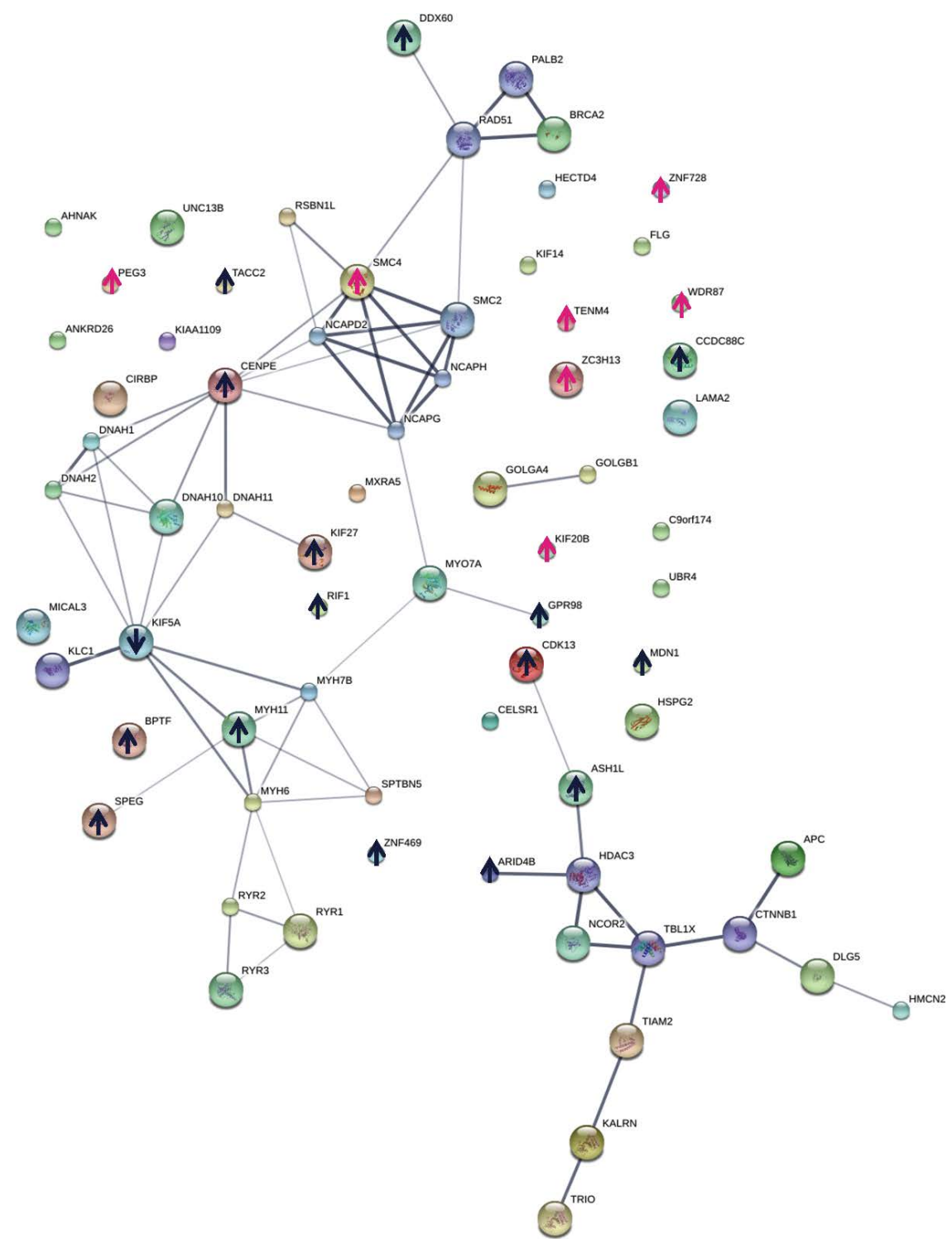

Fig. 6 Protein-protein interaction map of $> \pm 4.01$-fold proteins expressed in blue, $\mathrm{AgNO}_{3}$ and pink, AgNP compared to the control. The majority of proteins were up-regulated (up-arrow), with only one protein was down-regulated in $\mathrm{AgNO}_{3}$.

Table 2 Top 5 potential pathways of $> \pm 4.01$-fold expressed proteins with unique peptide counts, identified in $\mathrm{AgNO}_{3}$ compared to control

\begin{tabular}{clc}
\hline $\begin{array}{c}\text { Pathway } \\
\text { ID }\end{array}$ & \multicolumn{1}{c}{ Pathway description } & $\begin{array}{c}\text { False discovery } \\
\text { rate/FDR }\end{array}$ \\
\hline GO:0016568 & $\begin{array}{l}\text { Chromatin modification } \\
\text { GO:0016575 }\end{array}$ & $\begin{array}{l}\text { Histone deacetylation } \\
\text { GO:0030071 }\end{array}$ \\
$\begin{array}{l}\text { Regulation of mitotic metaphase/ } \\
\text { anaphase transition }\end{array}$ & $6.75 \times 10^{-4}$ \\
GO:0043933 & $\begin{array}{c}\text { Macromolecular complex subunit } \\
\text { organization }\end{array}$ & $6.75 \times 10^{-4}$ \\
GO:0045814 & $\begin{array}{c}\text { Negative regulation of gene } \\
\text { expression, epigenetic }\end{array}$ & $6.75 \times 10^{-4}$ \\
\hline
\end{tabular}

high-throughput workflow ${ }^{20}$ with the increase of robustness and reproducibility. ${ }^{21}$ The combination of proteomics and STITCH, an online protein-chemical interactive platform, would promote the power of addressing the underlying mechanistic toxicological
Table 3 Top 5 potential pathways of $> \pm 4.01$-fold expressed proteins with unique peptide counts, identified in AgNP compared to control

\begin{tabular}{clc}
\hline $\begin{array}{c}\text { Pathway } \\
\text { ID }\end{array}$ & \multicolumn{1}{c}{ Pathway description } & $\begin{array}{c}\text { False discovery } \\
\text { rate/FDR }\end{array}$ \\
\hline GO:0007076 & Mitotic chromosome condensation & $2.26 \times 10^{-9}$ \\
GO:0000070 & $\begin{array}{c}\text { Mitotic sister chromatid } \\
\text { segregation }\end{array}$ & $1.80 \times 10^{-5}$ \\
GO:0006367 & $\begin{array}{c}\text { Transcription initiation from RNA } \\
\text { polymerase II promoter }\end{array}$ & $1.04 \times 10^{-4}$ \\
GO:0007067 & Mitotic nuclear division & $3.91 \times 10^{-4}$ \\
GO:0030261 & Chromosome condensation & $1.88 \times 10^{-3}$ \\
\hline
\end{tabular}

pathways of NPs. In this study, we appraised the applicability of using LC-MS/MS-based proteomics to study the alteration of protein expression, coupled with bioinformatics to identify the toxicological pathways of AgNP, in which we established the partial difference from $\mathrm{AgNO}_{3}$. 
Similar toxicological pathways identified in both $\mathrm{AgNO}_{3}$ and AgNP involved in cell-cycle progression. According to STITCH Functional pathway enrichment analysis, AgNP induced the alteration of proteins functioned in mitotic chromosome condensation (GO:0007076), mitotic sister chromatid segregation (GO:0000070), mitotic nuclear division (GO:0007067), and meiotic chromosome condensation (GO:0010032). It was previously reported that various AgNPs interfered with the normal progression of the cell cycle. For instance, Asharani and colleagues found that $25 \mu \mathrm{g} / \mathrm{mL}$ starch-coated AgNP promoted the accumulation of both U521 and IMR-90 in $\mathrm{G}_{2} / \mathrm{M}$ phase. ${ }^{22}$ $\mathrm{G}_{2}$ arrest was also observed in another study using Jurkat $\mathrm{T}$ cells treated with $0.1-0.5 \mathrm{mg} / \mathrm{L} \mathrm{AgNP}(<100 \mathrm{~nm})$ along with the increase in the number of cells in S-phase. ${ }^{23}$ The gene expression study using microarray revealed the increase in the expression of checkpoint-related genes; BIRC5, BUB1B, CCNA2, CDC25B, $C D C 20$, and $C S K 2$ in $\mathrm{HepG} 2$ cells treated with $1 \mathrm{mg} / \mathrm{L}$ polyethyleneimine-stabilized $\mathrm{AgNP}(7-10 \mathrm{~nm})$ as well as in cells treated with $\mathrm{Ag}_{2} \mathrm{CO}_{3}$ and polystyrene NP. GO functional classification analysis indicated that genes classified in M-phase and microtubule-based process were up-regulated, which were similarly affected in all treatment groups. The interference to the cell cycle process in both ionic and nanoparticulate silver was also reflected by a cell viability assay, which indicated the effect of silver to cell-cycle progression regardless of forms. ${ }^{24}$ Similar identification was elucidated in our study. We also observed the effects of $\mathrm{AgNO}_{3}$ on the expression of proteins involved in cell cycle pathways, i.e. chromatin modification (GO:0016568), histone deacetylation (GO:0016575), and regulation of mitotic metaphase/anaphase transition (GO:0030071). Foldbjerg et al. (2012) also indicated that at $48 \mathrm{~h}$ of exposure, both citrate-stabilized $\mathrm{AgNP}$ in the concentration of $\mathrm{EC}_{20}$ and $\mathrm{AgNO}_{3}$ in the concentration of $\mathrm{EC}_{10}$ had an impact on regulation and maintenance of cell cycle in A549 cells. Although at $24 \mathrm{~h}$ of exposure, these results were only observed in AgNP treatment. ${ }^{25}$

The impact of silver on the cell cycle might be explained by $\mathrm{Ag}^{+}$. AshaRani and colleagues suggested the oxidation of AgNP in cell culture medium to release ionic silver, caused cell arrest, and DNA damage. ${ }^{22}$ In this study, we quantified approximately $70 \%$ of AgNP dissolved into ionic silver in the medium, which supported that released $\mathrm{Ag}^{+}$had an impact on cell cycle. A disturbance in the cell-cycle progression usually reflects the event of DNA damage, which consequently leads to oxidative stress. $^{22}$ During DNA damage, cells are accumulated in gap ${ }_{1}$ $\left(\mathrm{G}_{1}\right)$, DNA synthesis $(\mathrm{S})$, or in gap $_{2} /$ mitosis $\left(\mathrm{G}_{2} / \mathrm{M}\right)$ phases to undergo DNA repair. ${ }^{26}$ Although the effects of AgNPs on the cell-cycle process were previously established with the indication of DNA damage, oxidative damage, and inflammation, ${ }^{22,23}$ we did not identify any of these subsequent pathways in our study, which might be explained by the concentration. In this study, we chose a low cytotoxic concentration of $\mathrm{LC}_{10}$ of both types of silver for proteomics, which might be below the threshold to trigger the cytotoxic effects of DNA damage or oxidative stress.

Distinctive toxicological pathways identified in $\mathrm{AgNO}_{3}$ treatment were macromolecular complex subunit organization (GO:0043933) and epigenetic negative regulation of gene expression (GO:0045814) enriched by STITCH pathway analysis. These relate to the cellular organization and regulation of metabolic process of macromolecule, respectively. Ionic Ag had been reported to decrease the expression of proteins involved in protein synthesis and ATP production in E. coli. ${ }^{27}$ Moreover, at low cytotoxic concentration of $5 \mu \mathrm{g} / \mathrm{mL}, \mathrm{Ag}^{+}$ affected proteins in fatty acid and energy metabolism in Caco-2 cells after $24 \mathrm{~h}$ of exposure. ${ }^{28}$ The specific pathway identified from AgNP treatment group was transcription initiation from RNA polymerase II promoter (GO:0006367), which engages in the nucleic acid metabolic process. At non-cytotoxic concentration, AgNP had been reported to affect the pathways of protein folding, protein synthesis and modification, cellular assembly and organization. ${ }^{25,28}$ Although the toxicological pathways of ionic Ag and AgNP were previously reported, to the best of our knowledge, the cellular organization and regulation of metabolic process of macromolecule from $\mathrm{AgNO}_{3}$ treatment, and nucleic acid metabolic process from AgNP were not informed before.

In conclusion, we evaluated the feasibility of using LC-MS/ MS-based proteomics-coupled with bioinformatics to elucidate and distinguish the toxicological pathways from ionic and nanoparticulate silver. We supported that this platform was practical to establish the similarity, explained by the dissolution of nanosilver into ionic silver, and the difference in toxicological pathways between two types of silver. This finding exhibited the feasibility of this platform for the identification of adverse outcome pathways of different forms of test substances. This technique offered the high efficiency for a toxicological screening of a diversity of substances, importantly nanoparticles as these materials are rapidly developed into many sizes, forms, and coatings. At present, a large variety of consumer products contain nanomaterials, LC-MS/MS-based proteomics-coupled with bioinformatics would be a powerful approach to screen the risk of these materials in the nano-enabled products.

\section{Conflict of Interest}

All authors declare not to have any conflicts of interest.

\section{Funding}

This work was supported by National Nanotechnology Center, NSTDA, Thailand [grant number: P1752540].

\section{Acknowledgements}

The authors would like to thank Nonlinear Dynamics for the free-trial of Progenesis ${ }^{\circledR}$ QI for Proteomics, Ms. Kasamechonchung for helping with ICP-MS, as well as BIOTEC and NCTC for the access to all equipment used in this study.

\section{References}

1. K. B. Riaz Ahmed, A. M. Nagy, R. P. Brown, Q. Zhang, S. G. Malghan, and P. L. Goering, Toxicol. in Vitro, 2017, 38, 179.

2. L. A. Austin, M. A. MacKey, E. C. Dreaden, and M. A. ElSayed, Arch. Toxicol., 2014, 88, 1391.

3. H. J. Johnston, G. R. Hutchison, F. M. Christensen, S. Peters, S. Hankin, K. Aschberger, and V. Stone, Nanotoxicology, 2010, 4, 207.

4. C. Batchelor-McAuley, K. Tschulik, C. C. M. Neumann, E. Laborda, and R. G. Compton, Int. J. Electrochem. Sci., 2014, 9, 1132.

5. A. Kermanizadeh, B. K. Gaiser, M. B. Ward, and V. Stone, Nanotoxicology, 2013, 7, 1255.

6. P. V. AshaRani, S. Sethu, H. K. Lim, G. Balaji, S. 
Valiyaveettil, and M. P. Hande, Genome Integr., 2012, 3, 1.

7. T. Zhang, L. Wang, Q. Chen, and C. Chen, Yonsei Med. J., 2014, 55, 283.

8. X. Hu, D. Li, Y. Gao, L. Mu, and Q. Zhou, Environ. Int., 2016, 94,8 .

9. T. Benn, B. Cavanagh, K. Hristovski, J. D. Posner, and P. Westerhoff, J. Environ. Qual., 2010, 39, 1875.

10. M. Carrera, B. Cañas, and J. M. Gallardo, J. Proteomics, 2013, 78, 211.

11. M. Choi, Z. F. Eren-dogu, C. Colangelo, J. Cottrell, M. R. Hoopmann, E. A. Kapp, S. Kim, H. Lam, T. A. Neubert, M. Palmblad, B. S. Phinney, S. T. Weintraub, B. Maclean, and O. Vitek, J. Proteome Res., 2017, 16, 945.

12. B. Huang, H. Lin, and Y. Chang, J. Funct. Foods, 2015, 19, 629.

13. M. Kuhn, C. von Mering, M. Campillos, L. J. Jensen, and P. Bork, Nucleic Acids Res., 2008, 36, D684.

14. C. Putim, N. Phaonakrop, J. Jaresitthikunchai, R. Gamngoen, K. Tragoolpua, S. Intorasoot, U. Anukool, C. S. Tharincharoen, P. Phunpae, C. Tayapiwatana, W. Kasinrerk, S. Roytrakul, and B. Butr-Indr, Arch. Microbiol., 2018, 200, 299.

15. R. Mogire, H. Akala, R. Macharia, D. Juma, A. Cheruiyot, B. Andagalu, M. Brown, H. El-Shemy, and S. Nyanjom, PLoS ONE, 2017, 12, e0186364.

16. P. Sanguansermsri, H. Jenkinson, J. Thanasak, K. Chairatvit, S. Roytrakul, S. Kittisenachai, D. Puengsurin, and R.
Surarit, PLoS ONE, 2018, 13, e0208317.

17. L. Tuli and H. W. Ressom, J. Proteom. Bioinform., 2009, 2, 416.

18. S. Onsurathum, O. Haonon, P. Pinlaor, C. Pairojkul, N. Khuntikeo, R. Thanan, S. Roytrakul, and S. Pinlaor, Tumor Biol., 2018, 40, 1.

19. A. Rogowska-Wrzesinska, M.-C. Le Bihan, M. ThaysenAnderson, and P. Roepstorff, J. Proteomics, 2013, 88, 4.

20. Y. V. Karpievitch, A. D. Polpitiya, G. A. Anderson, R. D. Smith, and A. R. Dabney, Ann. Appl. Stat., 2010, 4, 1797.

21. S. E. Ong and M. Mann, Nat. Chem. Biol., 2005, 1, 252.

22. P. V. AshaRani, G. L. K. Mun, M. P. Hande, and S. Valiyaveettil, ACS Nano, 2009, 3, 279.

23. H. Eom and J. Choi, Environ. Sci. Technol., 2010, 44, 8337.

24. K. Kawata, M. Osawa, and S. Okabe, Environ. Sci. Technol., 2009, 43, 6046.

25. R. Foldbjerg, E. S. Irving, Y. Hayashi, D. S. Sutherland, K. Thorsen, H. Autrup, and C. Beer, Toxicol. Sci., 2012, 130, 145.

26. K. Ishikawa, H. Ishii, and T. Saito, DNA Cell Biol., 2006, 25, 406 .

27. M. Yamanaka, K. Hara, and J. Kudo, Appl. Environ. Microbiol., 2005, 71, 7589.

28. A. Oberemm, U. Hansen, L. Böhmert, C. Meckert, A. Braeuning, A. F. Thünemann, and A. Lampen, J. Appl. Toxicol., 2016, 36, 404. 